\title{
Alliance Management at Merck: Establishing an Operational 100-Day Plan for Alliance Launches and Management
}

\author{
Elmar Hörner
}

\begin{abstract}
Pharmaceutical industry faced many challenges in the past 20 years that led to a change in business models which is still ongoing. One of the adaptions is the increase in importance and number of strategic alliances.

This thesis looks at the launch phase of an alliance and proposes an operational 100-day plan for the use during different sub-phases. This plan is validated by a survey with alliance managers at Merck KGaA. The survey evaluates specifically their perception on timely involvement into the transition activities from business development to alliance management, the governance structure and metrics of alliances and collects feedback on the proposed 100-day plan.

The contents of the plan are considered as useful for the launch of an alliance by the survey participants and their feedback shows opportunities to further improve the best practices at the alliance management department as a follow-up after completion of the thesis.
\end{abstract}

\section{Introduction}

The past two decades have seen a shift in how and where medicines are being discovered, developed and marketed. Factors like

- reduced efficiency of the research and development (R\&D) process

- increased competition while major blockbusters lost their IP protection

- cost pressure from payers including the need to show efficacy in relatively small patient sub-populations

- new technological possibilities with the long-term goal of personalized healthcare and healing instead of live-long treatment

- higher transparency in global market access and pricing processes

and many more led to the need for changed business models of pharmaceutical companies.

\footnotetext{
E. Hörner $(\bowtie)$

Merck Healthcare KGaA, Darmstadt, Germany

e-mail: elmar.hoerner@merckgroup.com
} 
One of the adaptions is the increased importance and number of alliances. When not managed properly right from the start, the risk is high for failure in meeting the objectives. The alliance management plays a critical role in the setting of the alliance governance model and the continuous supervision of the processes and results of the partnership.

This study provides an overview on the different aspects of alliances with focus on the role and skills of Alliance Management (AM) during the lifecycle of the partnership. Especially during and after the transition phase from negotiation to alliance launch the important tasks are the setup of governance structure and the definition and continuous evaluation of the metrics.

A checklist is proposed that can be used by the Alliance Managers (AMs) for the planning of steps and decisions during the first 100 days of an alliance. This 100-day plan was improved and confirmed by feedback of the alliance managers at Merck KGaA.

After this short introduction, the following Sect. 2 discusses the already mentioned need for alliances and their importance in pharmaceutical industry more in detail. Thereafter, the nature and types of interfirm cooperations with focus on strategic alliances are shown in Sect. 3, together with the role of the alliance management department and manager.

A short history of Merck KGaA and its alliance management with recent examples explain in Sect. 4 the framework in which the main outcome of this thesis- the operational 100-day plan as shown in Sect. 5-shall be applied. This kind of checklist is then assessed and the results of the survey with alliance managers are discussed in Sect. 6. A conclusion and the further outlook finalize this thesis with Sect. 7.

The focus of the work was directed towards the practical aspects of alliance management and the theoretical backgrounds and motivations for alliance formation, various governance configuration models, economical theories (e.g. transaction cost economics or resource-based view), partner fit etc. have not or only in short been discussed.

Furthermore, the studies focus on the initial phase of an alliance. Other phases like partner selection, extension or termination are not discussed except for the general lifecycle of an alliance as mentioned in Sect. 3.2.

\section{The Importance of Alliances for the Pharmaceutical Industry}

\subsection{The Problem "Productivity Paradox"}

The pharmaceutical industry is a highly innovation-driven business which used to have an average sales growth rate of $11 \%$ per year from 1970 until 2004. Since then, the annual growth was reported by members of the Pharmaceutical Research and 
Manufacturers of America (PhRMA) association always below $8 \%$ or even negative (-6.2\% in 2012). The R\&D costs increased from below 15\% of sales before 1990 to more than $21 \%$ in 2017 (all data from PhRMA 2018)

The so-called "productivity paradox" describes the situation that despite rising $R \& D$ costs the pipeline output of pharmaceutical industry is low and declining. The annual statistics of US Food and Drug Administration (FDA) about the number of approvals of new molecular entities (NMEs) was slightly above 20 per year throughout 1980s, raised above 30 during 1990s with the highest number of approvals (51) in 1996. This was connected with some legislative changes which allowed FDA a significant increase in personnel and a reduction in backlog of pending registrations. Since then and during the 2000s the average number of yearly approvals fell again back to 20-25. While the numbers raised again during the 2010s to an average of slightly above 30 like in 1990s (2013: 27; 2014: 41, the highest number since 1996), these numbers have to be regarded in comparison to the steadily raise in $R \& D$ costs and the breakdown to the rate of successful companies.

Munos (2009) assessed the drugs that have been registered at US FDA over a period of 60 years (1950-2008). One of the findings was that the number of approvals of NMEs per year was the same at the end of this period as it was at the beginning. No company was able to achieve the approval of two or three NMEs per year which is the estimated number for meeting own growth objectives of big pharmaceutical companies. On average, one NME was approved every 6 years. In parallel, the costs per NME increased exponentially at an annual rate of more than $13 \%$. Munos concludes that the "R\&D model [...] is showing signs of fatigue: costs are skyrocketing, breakthrough innovation is ebbing, competition is intense and sales growth is flattening. This cluster of symptoms has often foretold major disruption in other industries".

Scannell et al. (2012) evaluated the pharmaceutical R\&D efficiency in a period from 1950 to 2010. The comparison of R\&D budget vs. NME approvals showed that the number of approvals per $\$ 1$ billion budget declined almost every 9 years by half. The rate of decline was shown as quite constant over different 10 -year periods in the overall 60-year period.

Some reasons for the decline of R\&D productivity and potential solutions have been discussed by Kramer (2016). He sees the challenges in the

- Raising R\&D costs due to increasing scientific and regulatory requirements for the approval of new drugs, including the data on safety

- High attrition rate of drug candidates in phase II/III clinical trials

- Increasing competition by generics and biosimilars and between companies for attractive targets in human metabolism

- Increasing cost pressure of health organizations and healthcare providers

- Increasing pressure from public health for evidence on significant improvements compared to existing therapies

- Shortened time to regain R\&D costs prior to the expiry of patent protection due to longer development times 


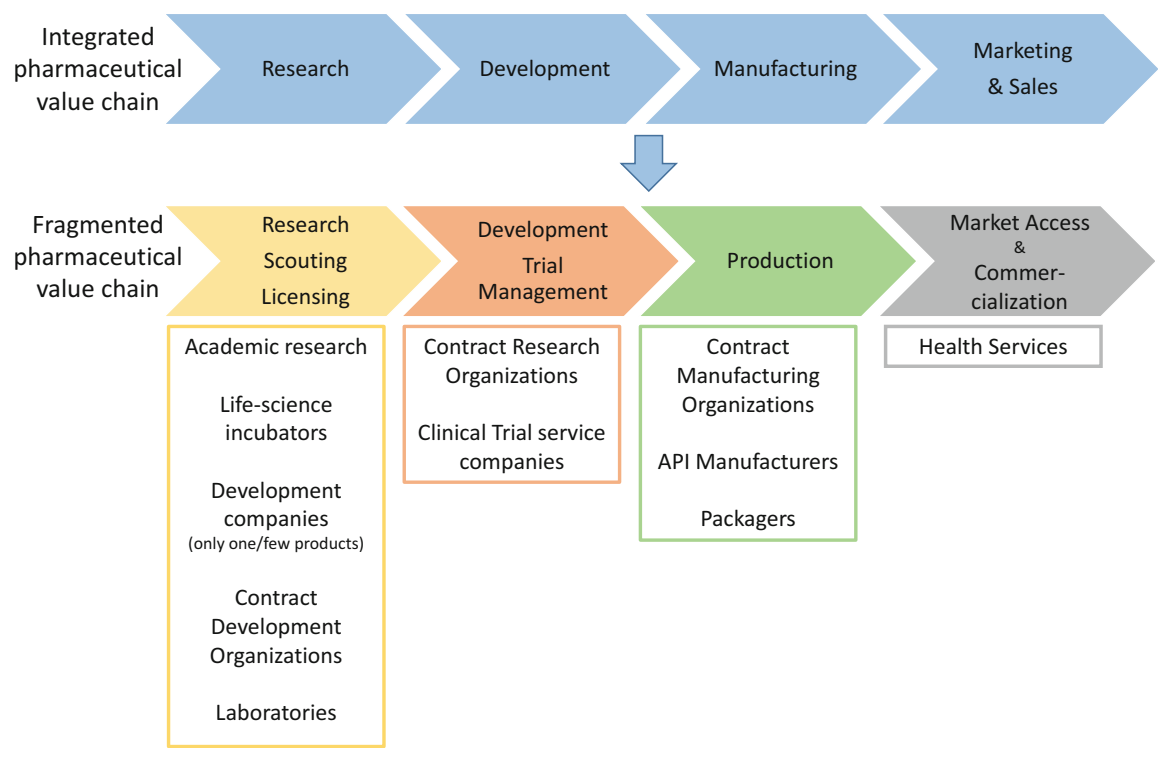

Fig. 1 The fragmented pharmaceutical value chain. Adapted from Capo et al. (2014) and IMAP (2012). API: Active Pharmaceutical Ingredient

Capo et al. (2014) see in addition to the above-mentioned stringent approval requirements the $R \& D$ cost driver in the "orientation of research towards increasingly complex pathologies, [that] have implied larger, more costly and internationally based R\&D activities". These challenges have led on the one hand to a consolidation of the industry via M\&A activities, but also to a cultural change over last 20 years. The scientific R\&D process and the subsequent value chain within one pharmaceutical company was disrupted into the orchestration of specialized contributors to specific parts of the chain as shown in Fig. 1.

\subsection{Cooperation as a Potential Solution}

The fragmentation of the pharmaceutical value chain as one potential solution to the paradigm shift (other solutions would be e.g. focus on niche markets or cost cuts in R\&D which shall not be discussed here further) can be accomplished only with strong and multi-faceted interfirm cooperation. With such cooperation, companies can

- share skills, risks, costs and rewards

- bundle and complement resources

- create synergetic effects

- enter new and additional markets

- increase their (combined) competitiveness vs. others on the same market. 
The interfirm cooperation has some benefits but brings also some risks. While scientific and commercial failure is not specific to cooperation but common to all R\&D projects, Thong (2016, pp. 45-52) identifies two (elevated) risks and a general consequence when two or more partners have to coordinate:

Execution risk: Thong defines this as "the risk arising from being unable to resolve unanticipated problems [...] over the course of the project's execution". Like scientific and commercial risk that is partly applying to all R\&D projects, but with more complex communication, problem-solving and decision-making processes higher than for internal projects. Inflexible project management (adherence to preset deliverables and timelines) and narrow project goals can further increase the execution risk.

Collaboration risk: These are added complications due to the work with one or more external partners. Fundamental differences in "organizational missions, processes, and culture [...] create confusion and tension". Different needs and expected outcomes from a project can lead to a higher risk for project failure.

Collaboration tax: The elevated execution risk and the additional collaboration risk is called the collaboration tax by Thong (other authors use also the terms partnering or alliance tax). Before entering into an interfirm cooperation, each partner shall understand and evaluate the related collaboration tax. One mitigation is the assignment of a dedicated alliance management (AM) department within the company and of an alliance manager role within each project to minimize the number of issues or allow their early resolution as discussed in Sect. 3.3.

The specifics of (strategic) alliances as one form of interfirm cooperation, its differences to other forms and the lifecycle shall be shown in the following. Also the role and capabilities of the alliance management function and manager will be presented as well as general alliance structures and the evaluation of alliances.

\section{The Nature of Alliances}

\subsection{Definitions and Types of Alliances}

The terms interfirm cooperation and alliance are diffusely used in literature. Sometimes alliance is used as an overall term, sometimes only as a specific form of cooperation.

A more general definition is used by Stafford (1994): "Strategic alliances are long-term co-operative partnerships involving vendor, customer, competitor, or industry-related firms and are used to achieve some competitive advantage. They may include joint ventures, supplier and distributor agreements, licensing arrangements, just-in-time systems, and research consortia, to name just a few."

Albers (2005, p. 9) defines every cooperative interorganizational relationship as "an alliance if a formal agreement exists between the actors that specifies the activities which are the subject of cooperation. Thus, not all cooperative relationships among firms are alliances, but all alliances span cooperative relationships 
among firms." He lists as characteristics of an alliance the voluntariness, fixation by agreement, exchange and/or pooling of resources and the sharing of benefit and control.

A more restricted view by Yoshino and Rangan (1995, p. 4-5) defines "a strategic alliance as possessing simultaneously the following three necessary and sufficient characteristics": Two or more firms remain independent, share benefits and control and "contribute to a continuing basis in one or more key strategic areas".

Suen (2005) combines this definition with the specifics by Gomes-Casseres (1999, p. 34): Each partner has only limited control and the cooperation is based on "an incomplete contract". "Because the partners remain separate firms, there is no automatic convergence in their interest and actions. As a result, to deal with unforeseen contingencies the partners need to make decisions jointly."

DePamphilis (2018, p. 553) uses the overall term of "Business Alliances" which covers a variety of partnerships (Joint Venture, Strategic Alliances, Equity Partnerships, Licensing, Franchising, Network Alliances, Exclusive Agreements) with different characteristics but "the common goal of the partners are the sharing of risks, rewards and control".

The Association of Strategic Alliance Professionals (ASAP) says about the motivation for partnering: "Typically, strategic alliances have a broad and longterm impact on corporate performance and valuation. Often, strategic alliances are formed to create a competitive advantage for the partners in their respective markets" (https://www.strategic-alliances.org/page/alliance_definitions).

Merger and Acquisitions (M\&A) activities are closely related to alliances and often seen as a kind of definitive, non-temporary alliance with a high level of control. The main differences are a higher investment, interest of controlling, less flexibility and the joint organizations become either one or belong to the same corporate parent (Gomes et al. 2011, p. 7f.).

The range of strategic alliances from pure contractual, non-equity based alliances like market transactions to equity-based alliances with its most definitive form of an acquisition is shown in Fig. 2.

There are three main types of alliances which can be assigned to the three main stages of the pharmaceutical value chain as shown in Fig. 1. Austin (2008, p. 166) differentiates accordingly:

- Research alliances for discovery, target and lead molecule identification, for assays, mechanisms etc.

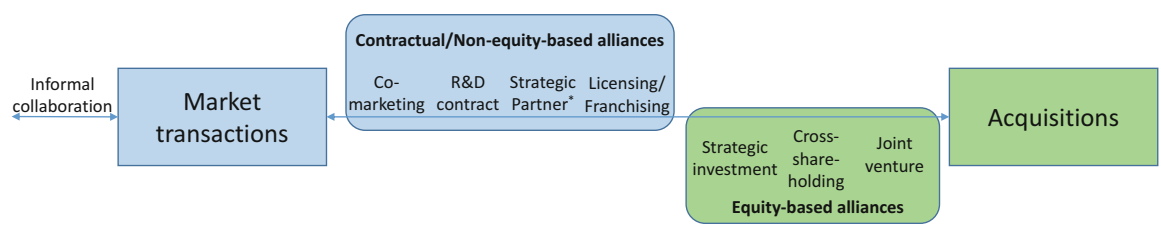

Fig. 2 Range of alliances from market transactions to acquisitions. Adapted from (Peng 2014, p. 213) and (Herrmann and Dressel 2014). *E.g. strategic supplier, distributor, service provider 
- Development alliances for the formulation, chemistry and manufacturing processes of pharmaceutical products

- Commercial alliances for co-promotion and in the form of joint ventures

The alliance type can also be defined by the underlying business model and activities for which the partner agree the sharing:

- In-licensing: A company (licensee) acquires intellectual property from another company (licensor) to produce and/or market a product or to use a technology, platform or software for research and production activities.

- Out-licensing: Licensor commercializes the internal research results by giving licenses to another company for further development or commercialization in markets or market segments that are not of interest or not accessible by the licensor.

- Co-Development: Mutual development by companies that complement their available technologies, molecules, products and know-how.

- Co-marketing or -promotion: Two partners share their commercial activities for a product or range of products, but usually in different markets/countries.

\subsection{The Lifecycle of Alliances}

Each alliance undergoes usually several stages from its initialization to its termination as shown in Fig. 3.

The different phases are a synthesis of the ones proposed by (Thong 2016) and (Tjemkes et al. 2018). Steinhilber (2008, p. 18) uses the terms Evaluating, Forming, Incubating, Operating, Transitioning and Retiring to describe the lifecycle of an alliance. Beside the different naming of the phases, some overlaps or sub-division which results in a slightly higher number of steps, the general lifecycle model of alliances is well aligned between the scholars.

The first steps include the search for and evaluation of potential partners. Once such a partner was identified and first negotiations were successful, a due diligence (DD) is conducted to evaluate the partner's suitability and the asset which is in scope of the alliance. These steps and the negotiations about the contract are led by Business Development (BD) department. The AM department gets involved only

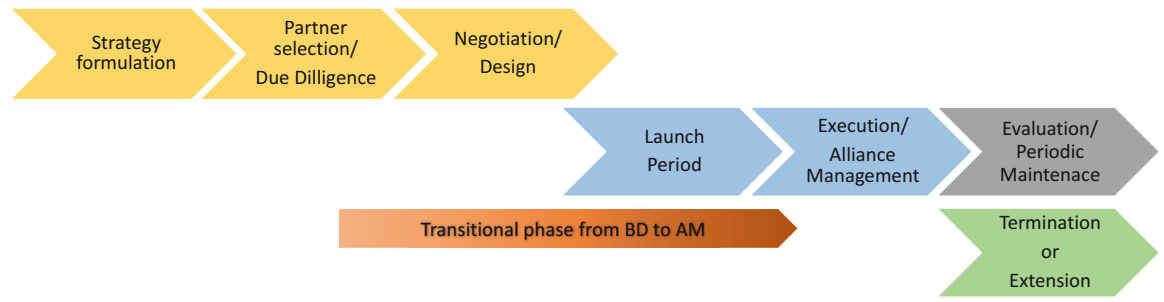

Fig. 3 Typical stages of an alliance. Adapted from (Thong 2016) and (Tjemkes et al. 2018) 
during the late-stage of contract negotiations and takes over completely for preparation of alliance launch. BD's involvement is simultaneously decreasing during this period.

This transitional phase as indicated with the red arrow in Fig. 3 is critical for the success of an alliance. Not only the handover from the BD to the AM responsible is needed to ensure a complete knowledge transfer and seamless launch, but also the transition from the DD team to the operational team will minimize the risk of failure.

And that risk of failure is still high: There are numerous studies and it seems that with all differences in research approaches a failure rate of $50 \%$ is not exaggerated (Man 2005; Duysters et al. 2012). Tjemkes et al. (2018, p. 7f.) address three key findings:

- Each development stage of an alliance requires attention to different questions and decisions.

- Underestimation of challenges by different alliance objectives by the partners or diverging company characteristics/culture

- Institutionalization of the alliance know-how and know-what in a company ("alliance capabilities") increases the probability of success.

\subsection{The Role of the Alliance Management}

The partners must invest continuous efforts and adjustments to make an alliance successful (Bamford et al. 2003, p. 5). The establishment of a dedicated AM function as proposed by Tjemkes was identified as a key advantage in different studies. Their focus is more on the internal operations of alliance partners than on the relationship between the partner companies. "[...] The experience a company has with alliances and the quality of alliance management are key success factors, which increase alliance success" (Man 2005).

(Alliance) Capabilities can be built by developing "mechanisms or routines that are purposefully designed to accumulate, store, integrate, and diffuse relevant organizational knowledge acquired through individual and organizational experience" (Kale et al. 2002). This study comes to the conclusion that companies increase their alliance success rates by investing into "a dedicated alliance function designed to capture and apply the know-how from its alliance experience [...]".

According to Dyer et al. (2001, p. 39), the dedicated alliance function has the role to provide

- knowledge management and learning

- external visibility and support

- internal coordination and legitimacy

- alliance assessment and intervention to fix problems.

- With these activities, the function creates value by

- improving alliance success rates

- higher probability for stock-market gains

- enlarging the ability to form more alliances and to attract better partners. 
The mechanisms for effective alliance capabilities are proposed in six categories (adapted from Heimeriks et al. (2009); Heimeriks and Duysters (2007)): Dedicated alliance function on an adequate hierarchy level, specific alliance training (e.g. negotiation, cultural competences), alliance managers (tasks and skills as below), tools (e.g. databases, templates, decision trees, Key Performance Indicators [KPIs]), processes (e.g. knowledge exchange, metrics, bonus system) and support by external parties (e.g. consultants, financial and legal experts, mediators).

The tasks of an alliance manager are identified by Thong (2016, p. 165f.) as follows:

Contract management: Monitoring the contractual obligations like milestone payments, resolving issues in case of different interpretation of the contract.

Monitoring the progress: Defining and reporting of KPIs and leading periodic health checks.

Process management: Establishing smooth operation, preparation of governance meetings and decision-making.

Acting as ambassador of the alliance at the partner and within the own organization.

Alignment and relationship management: Leading efforts for increased mutual understanding and trust.

Strategic value and risk management: Identifying and focusing on value drivers as well as identifying and mitigating key risks.

Change management: Anticipating changes and manage transitions smoothly.

An ideal AM should have strong communication and networking skills, high credibility, is curious but has also courage and does not shy away from conflicts (Thong 2016, p. 181f.). ASAP developed skill trainings in context competencies (not exclusive to AM, e.g. communication, time management, conflict resolution, contract negotiation, project management, change management, leadership), core competencies (AM-specific in the areas of alliance capabilities [governance structure, alliance cycle, conflict resolution], skills development [e.g. alignment, launch, governance, metrics, termination], collaboration) and business/industry knowledge (e.g. financial analysis, business sector knowledge, sales processes) (ASAP 2016; Nevin 2016, p. 271ff.).

\section{Merck KGaA and Its Alliances}

\subsection{History of Merck KGaA}

To understand the environment for which this thesis generates a launch plan of strategic alliances, this chapter shall give a short introduction about the history of Merck KGaA and its business units. A very detailed and complete history of Merck can be found in the recently published book for the 350-year anniversary by Scholtyseck et al. (2018). 
Merck sees itself as "a leading science and technology company in healthcare, life science and performance materials" and the "world's oldest pharmaceutical and chemical company". The company was founded in 1668 by Friedrich Jacob Merck in Darmstadt, Germany. In 1827, Emanuel Merck conducted research in the chemistry of natural plant substances and prepared alkaloids which he offered under the name "Cabinet of Novelties" as the first kind of chemically standardized and relatively pure pharmaceutical substances. This allowed the expansion of the business to a global and industrial level.

The commercialization for the first technical applications of liquid crystals in 1968 under the brand licristal ${ }^{\circledR}$ for the first technical solutions built the start of today's business unit Performance Materials which includes pigments and other functional materials. Around $70 \%$ of all liquid crystals worldwide are currently produced by Merck.

The production of chemicals, culture media and reagents for the R\&D activities in academic and commercial laboratories was also an early business. This was strengthened by the takeovers of the competitors Millipore Corporation in 2010 (Merck KGaA 2010) and Sigma-Aldrich in 2015 (Merck KGaA 2015) and resulted in the business unit Life Sciences. A range of around 300,000 products covers laboratory water systems, gene editing tools, antibodies, cell lines and many more.

Merck acquired in 2007 the Swiss company Serono S.A. (Merck KGaA 2007) for its Healthcare business which was a significant transformation of the previous portfolio of small molecules into the field of biotechnological products. Today, Healthcare is the biggest of the three business units of Merck and contributes with $45 \%$ and almost $€ 7$ billion net sales to the total net sales. The activities for biosimilars were divested in 2017 to Fresenius Kabi (Merck KGaA 2017a) and the consumer health business in 2018 to Procter \& Gamble (Merck KGaA 2018c).

Healthcare at Merck consists of a portfolio in the therapeutic areas of fertility, general medicines (diabetes, thryroids, cardiovascular), neurodegenerative diseases (mainly Multiple Sclerosis) and oncology. The distinct focus of current R\&D activities lies in the areas of oncology (therapies against e.g. solid tumors and hepatocellular cancer), immunology (therapies against e.g. psoriasis, osteaoarthritis, rheumatoid arthritis) and immuno-oncology (therapies against e.g. gastric, ovarian, colorectal or lung cancer).

Almost 53,000 employees in 66 countries generated in 2017 total net sales of $€$ 15.3 billion in all three business units of Merck. The R\&D budget was about $€ 1.2$ billion, with $68 \%$ or $€ 1.6$ billion of it for the healthcare business (Merck KGaA 2018a).

\subsection{Significant Biopharma Alliances of Merck}

Merck has a long history on alliances on both local and global level, on different activities (research, development, commercial), business models (in-, out-licensing, 
co-development, co-marketing) with a variety of different partners. Currently more than 100 alliances are managed by the responsible team as detailed in Sect. 4.3.

According to Merck's website, the company is looking to "source new compounds, gain access to the latest technology platforms and develop novel therapeutics for patients. Our goal is to craft a pipeline that is a mix of both internal and externally sourced assets that are in line with the company's growth goals and strategically fit with both commercial and developmental strengths" (https://www. merckgroup.com/en/company/partnering/collaboration/collaboration-in-healthcare/ strategic-focus-and-partnerships.html).

The most important strategic alliance was entered in 2014 with Pfizer Inc. for the co-development and later co-commercialization of a class of specific immunooncological compounds (anti-PD-[L]1) from both partners, in the meantime registered as Bavencio ${ }^{\circledR}$ (Avelumab). The contract included up to 20 immunooncology clinical development programs. Merck received an upfront payment of $\$ 850$ million - the biggest upfront deal payment in pharmaceutical industry at this time - and could receive regulatory and commercial milestone payments of up to $\$ 2$ billion Merck KGaA (2014). As an additional part of the contract, Merck received the right to co-promote Pfizer's oncological product Xalkori ${ }^{\circledR}$ (crizotinib) for the treatment of lung cancer in the US, Canada, Japan and other key markets.

Table 1 gives an overview about the different types of exemplary alliances which were entered between 2010 and 2018. The reference to the related press release with more background on the scope of the alliance is given below the table.

Table 1 Type and business models of Merck's selected alliances

\begin{tabular}{|c|c|c|c|c|}
\hline \multirow{2}{*}{$\begin{array}{l}\text { Type of } \\
\text { alliance }\end{array}$} & \multicolumn{4}{|l|}{ Business model of alliance } \\
\hline & In-licensing & Out-licensing & Co-development & Co-promotion \\
\hline Research & $\begin{array}{l}\text { Vertex }(2017 a, b) \text { ICR } \\
\text { (2018) }\end{array}$ & & & \\
\hline Development & Lupin (2014) & $\begin{array}{l}\text { Newron } \\
(2011)\end{array}$ & $\begin{array}{l}\text { BeiGene (2014) } \\
\text { Pfizer (2014) } \\
\text { CheckMate } \\
\text { (2018) } \\
\text { Leap (2018) } \\
\text { Vyriad (2018) }\end{array}$ & \\
\hline Commercial & Xian Janssen (2018a, b, c) & $\begin{array}{l}\text { Recordati } \\
(2010) \\
\text { BMS (2013) }\end{array}$ & & Pfizer (2014) \\
\hline
\end{tabular}

Recordati S.p.A (2010); Newron Pharmaceuticals S.p.A. (2011); BeiGene (2014); BMS: The Pharma Letter (2013); Lupin: Merck KGaA (2014); Vertex: Merck KGaA (2017b); ICR: Cancer Research UK (2018); Checkmate Pharmaceuticals (2018); Leap Therapeutics (2018); Vyriad Inc. (2018); Xian Janssen: Merck KGaA (2018b) 


\subsection{Alliance Management at Merck}

The advantage of a dedicated AM function within a company has been mentioned in Sect. 3.3. Such a department is established at Merck which shall—according to its own mission statement- "guide Merck to be recognized as preferred partner of choice in biopharma industry, maximizing the value of the partnerships." The goal is to "maximize short and long term value creation by increasing the effectiveness of a project via an efficient governance structure, driving transparent decision making, anticipating risks and leading the resolution of issues" (all information in this chapter is derived from Merck-internal material and presentations). The partnerships shall "deliver more, at higher quality, in time, at lower cost."

The department consists currently of ten AMs, based at sites in Germany, US and Latin America. That size is in the medium range: A study with 47 companiesrepresenting two-thirds of all companies that are members of the Biopharma Council of ASAP - found that $42 \%$ have departments with less than five people and another $42 \%$ consist of more than ten people (Twombly and Shuman 2010). Number and scope of alliances in the portfolio of each AM were part of the general statistics section in the survey (please refer to Sect. 6.1).

The main activities of AM per phase of the alliance lifecycle according to the department's handbook are as follows:

Prior to Deal Closure: Collaboration with BD; Input on contract sections regarding termination, governance, AM role, issues resolution; Nominate JSC members; Prepare KOM;

Alliance launch: Take lead from BD; Lead joint KOM; Communicate their roles and responsibilities (R\&R) to JSC members and project team; Align plans and joint objectives with partner;

Alliance Management: Lead JSC preparation meetings; Facilitate JSC meetings and drive decision making; Manage intra- and inter-company alignment;

Issue resolution: Recognize early signs of problems and address issues in advance; Lead issue resolution and act as single point of contact in resolving disputes;

Refreshing or Leveraging: Drive continuous improvement of the alliance; Re-negotiate and amendments of the contract; Enhance and redesign governance

Termination: Lead termination agreement negotiations; Prepare and drive winddown plan;

The AM department measures the long-term success with some KPIs to identify areas or alliances that need improvement. Seven KPIs have been identified as crucial for evaluation of success:

Effective Decision Making: Number of decisions made in the joint governance meetings, compared to total number of decisions asked to JSC.

Joint Objectives: Number of alliances with aligned joint objectives, compared to total number of alliances. 
Alliance opportunities identified: Opportunities (extension of territory or products/molecules in scope) identified with the existing partner and/or with the network of partners that became a $\mathrm{BD}$ project in the later stage.

Value creation: Incremental Net Present Value (NPV) created with all alliances.

Planned Termination: Execution of termination in accordance to the proposed plan.

First 100 days onboarding: Align and execution of 100-day plan. Qualitative deviations from initial plan are measured.

Alliance Management survey: Merck performance on Alliance Management (see also below). One KPI for all alliances in total. Merck conducts a survey with all its partners every 2-3 years. Feedback is collected on the perceived performance of governance, operations and alliance management. The results showed constant improvement of the alliances since 2008 in all areas.

\section{The Operational 100-Day Plan}

Based on the available literature about alliance management, an operational 100-day plan for alliance launch has been created as the main practical outcome of this thesis (see Appendix 1, available as online resource). This kind of checklist allows to formalize and harmonize the steps around the launch of an alliance and separates the whole period into five different phases as shown in Table 2.

The tasks of Phase I-Preparation of Alliance Launch include the first involvement of $\mathrm{AM}$ into the ongoing negotiations between $\mathrm{BD}$ and the partner to get first insights into partner's culture and strategic motivation, identify the stakeholders of both parties and establish relationship, gain knowledge about scope and strategy of the alliance, allow the first evaluation on suitable collaboration platforms and first alignment on governance and decision-making model and communication plans, prepare internal and joint Kick-off meetings (KOMs).

All these activities contribute to a successful knowledge transfer and allow a seamless and early launch of the alliance while avoiding unnecessary surprises. The timing of this phase should start early enough but also not too early. As long as there is significant uncertainty on the terms and probability of the deal, the involvement of Alliance Management is blocking resources without benefit. A shared risk-based

Table 2 Phases of an alliance launch as used in the operational 100-day plan

\begin{tabular}{l|l|l}
\hline Phase & Name & Timing \\
\hline I & Preparation of alliance launch & Day $-30^{\mathrm{a}}-0$ \\
\hline II & Alliance launch/develop alliance strategy & Day $0-14$ \\
\hline III & Execute alliance strategy & Day $15-89$ \\
\hline IV & Evaluate alliance strategy & Day $90-100$ \\
\hline V & Managing the alliance & Day $100+$ \\
\hline
\end{tabular}

${ }^{\mathrm{a}}$ The start of this phase could differ and depends on e.g. the PoS for successful deal closure 
decision should be made by the $\mathrm{BD}$ and $\mathrm{AM}$ departments regarding the best time to start with AM involvement. According to Bamford et al. (2003, pp. 111-112) "Expert opinions differ on whether those who will run the alliance should be included on the negotiation team. [...] Firms would be wise to choose a potential alliance manager to include on the deal team, after the initial partner screening and discussions of interest have taken place. [... Including them on the negotiating team can only improve the odds of success."

The Phase II-Alliance Launch/Develop Alliance Strategy starts with a distinct milestone-Day 0 - when the contract is finally signed by both parties and the related communication and press release (if applicable) are circulated. Around this day, the common platforms need to be initialized and internal KOMs of both parties arranged to align on company position and first steps. The discussions of Phase I regarding governance model, meeting formats and frequencies and other details have to be finally aligned.

The most important and critical step during this phase is the conduct of the joint KOM with the relevant stakeholders. Depending on the governance structure there could be several KOMs of each committee, decision body or working group. A reasonable order of such KOMs should be aligned. There could be reasons to start from top-down and hold the JSC first, or to clarify first things on a more operational level in the different groups and get endorsement by JSC only later. The KOM is preferably done as a workshop with physical presence and depending on the complexity of the alliance a few days might be required.

During Phase III-Execute Alliance Strategy the metrics of the alliance is established with regular quality reviews and KPIs. An alliance charter can be used to document the framework including background, scope, vision, metrics, milestones, infrastructure, governance structure and other aspects. With this setup the operational work can start for all contributors and the AM needs to keep an oversight in the early days of an alliance: To manage the internal alignment, to anticipate issues and to resolve them. The AM has to participate in most of the relevant meetings to stay in close contact. In addition, the facilitation of JSC meetings is of importance especially in the launch phase. But also the development of alternative options - the potential exit and termination-is not of minor interest even when everything looks promising. Robert Thong (2016, pp. 143-146) calls this phase the "honeymoon period", "when the activities are straightforward, the outcomes are predictable, and the inevitable personal frictions have not yet developed". This phase shall be used to "build the foundations of success, taking advantage of the positive feelings and goodwill on both sides to establish strong communication channels and foster trust".

At the end of the launch period in Phase IV-Evaluate Alliance Strategy, the time has come to run a self-assessment survey (or potentially even conduct a deeper gap analysis) on different levels (JSC and JPT) of the alliance and at both partners. Several aspects are usually evaluated by Merck's AM like

- the quality of presentations

- meeting preparation and conduct 
- discussion and escalation culture

- quality of decision-making

- overall satisfaction of the stakeholders

- suggestions for further improvement.

The results have to be thoroughly reviewed with focus on the areas of misalignment. The AM has to propose potential actions to close the gaps, document risks and issues and work on mitigation strategies.

The launch phase of the alliance is transferred after 100 days with this first evaluation round to Phase V-Managing the Alliance Strategy. Sharing the lessons learned during this phase with other AMs as well as with BD colleagues will improve the PoS for upcoming alliances.

For the running alliance the regular and ongoing tasks like

- facilitation of governance processes

- regular contact with project team

- long-term success metrics with e.g. surveys every 2 years

- resolution of issues

- contract amendments

- reporting and communication

- remain as vital tasks to ensure the achievement of alliance's objectives.

\section{The Online Survey on the 100-Day Plan}

To evaluate, validate and further improve the content of this checklist, an online survey was designed. The questionnaire consists of 24 questions which cover general statistics about the portfolio of each AM, the view of each AM on the alliance launch phase, questions on governance aspects, on evaluation of alliances and the feedback on the proposed 100-day plan. The online survey was sent to ten Merck Alliance Managers, of which nine contributed. In parallel they were provided with the 100-day plan to collect their feedback on it. The results are shown and discussed in the following, percentages may not add up to $100 \%$ due to rounding.

\subsection{General Statistics}

The different portfolio sizes of each AM are almost equally distributed: Two AMs each (22 percent) manage 1-5, 6-10 and more than 20 alliances, respectively. Three AMs (33\%) have 11-15 alliances in their portfolio. That is quite a big variety which can be explained by the differences in scope, size and priority of the alliances. A research alliance with multiple clinical trials, which is complemented by additional alliances for combination therapies with molecules from other partners, requires more attention than commercial alliances with a limited product and geographical 
scope. But there is also one AM with 1-5 alliances which were all commercial. On the other hand, one AM with more than 20 alliances has $70 \%$ with development activities.

According to the study "Practice of Alliance Management in the Biopharmaceutical Industry" by Twombly and Shuman (2010, p. 18) around 65\% of all respondents in mature AM departments (established longer than 5 years) manage one to five alliances. Compared to this result, the portfolios are much bigger for Merck's AMs. As already mentioned in Sect. 3.3, Merck's AM department is bigger than the ones in $50 \%$ of the 47 companies that participated in this study. One of their finding - that fits to the survey results-was that there is a tendency for bigger portfolios of each AM when alliance groups are larger. The mixed portfolio of the survey participants should allow the coverage of many possible scenarios with one single 100-day plan, once it has been revised in accordance with the collected feedback.

$21 \%$ of the managed alliances are related to research, $26 \%$ to development activities. The majority of almost $43 \%$ are commercial alliances which can have a limited product and geographical scope as already mentioned. As the other three types of alliances have also relevant numbers, the proposed design of the 100-day plan needs to fit to all types and their specific needs.

The majority of $61 \%$ are alliances where Merck licenses a technology, molecule, product or trademark from a partner. The alliances where Merck is giving a license to a partner or is co-developing products with a partner are almost equally distributed with 15 and 18 percent, respectively. Commercial (co-promotion or co-marketing) activities are not that common with only $6 \%$. The business model can depend also on the lifecycle of an alliance: Research and development projects can be transferred to commercial alliances after successful launch or the resulting product can be out-licensed to one of the partners or a third party.

The question whether the AMs have sufficient time for each partner and the internal team was answered quite indifferent: In the 44\% group (four AMs) with sufficient time, there are AMs which have only a few alliances but also one with the highest number. The situation is the same for the other 56\% (five AMs). Therefore, the number of alliances in the AM portfolio cannot be seen as the decisive factor. But it seems that there is also no correlation between the alliance types or business models and the answer to this question. AMs with mainly $R \& D$ alliances gave both possible answers. And AMs with pure or mainly commercial alliances did the same. Finally, also the age of alliances in the portfolio (please refer to question 1.5) is not relevant for the kind of answer. Further evaluation on this question should be considered in order to find a root cause and show options to improve efficiency of AM work and their relation to partners and joint teams while reducing potential stress levels.

Regarding the age of alliances in each portfolio there is a big variety. The oldest alliances have been established already more than 30 years ago and are still active, the youngest was signed only seven months ago. The average age ranges from 1 to 14 years. Four AMs have quite young alliances with an average age of around 3 years. 


\subsection{Alliance Launch Phase}

The average time from contract signature to KOM is almost 5 weeks in a range from less than 1 week to 8 weeks. The AMs were involved on an average 9 weeks before signature of the contract.

The study by Twombly and Shuman (2010, p. 20) showed that $67 \%$ of AMs from 47 companies were part of the DD team, including the role as advisors. They also were able to provide input into contract content. That fits in general to the actual results.

Five AMs (56\%) are now involved earlier than they used to be, four AMs (44\%) are not. The majority of six AMs $(67 \%)$ would prefer to become involved even earlier into the negotiations of the deal, three AMs (33\%) are fine with the current timing of involvement.

The quality of knowledge transfer from BD to AM was rated by one participant (11\%) only with 3 out of 10 points. Two AMs each (22 percent) score with 6 and 7 points, respectively. Four AMs (44\%) consider the quality of transfer with 8 points. That leads to an average rating of 6.8 out of 10 points which can be considered as acceptable, but leaves room for improvement.

\subsection{Governance of Alliances}

The number of alliances with and without JSC/JPT structures are almost equal. Four AMs have no alliances at all with JSC/JPT, one AM with almost only commercial alliances reported a low rate of $27 \%$ of them with JSC/JPT. The number of alliances four other AMs with JSC/JPT range from 43 to $80 \%$. The four AMs which manage alliances without any JSC/JPT gave the following explanations: The alliances are only of low complexity, supply agreements or patent licenses or an out-licensing agreement where the partner is responsible exclusively for decision-making. The five AMs with a mixed feedback provided the following statements on the reasons for not having JSC/JPT for some of their alliances: They are either too small or quite mature, concern only supply agreements, in-licensing or distribution agreements with low complexity, more transactional/vendor type relationships, in a discovery phase or pure research technology licenses.

Only three of the AMs (33\%) have an alliance charter or manual in place for at least one of their alliance, the majority of six AMs (67\%) have not. Two of the three AMs with alliance charter or manual manage portfolios of 11-15 and more than 20 alliances, respectively. More than $90 \%$ are commercial partnerships in both cases. It has to be highlighted that from the survey data it cannot be concluded that the charters or manuals are established for a commercial alliance. The third AM with alliance charter manages a portfolio of 6-10 alliances, with $29 \%$ commercial and $14 \%$ research alliances. Three AMs $(33 \%)$ have a regular communication to the joint 
committees or other stakeholders of at least one of their alliances, six AMs (67\%) have not.

The average satisfaction about the current governance effectiveness was rated by each three AMs with 8 and 9 out of 10 points (38\% each). Two AMs scored with 6 points $(25 \%)$. This results in an average rating of the governance effectiveness with 7.9 points which can be considered as quite good.

\subsection{Evaluation of Alliances}

Six AMs (67\%) have regular evaluations in addition to Merck's general AM survey every 2-3 years as mentioned in chapter 0 , three AMs (33\%) have not. The additional evaluations happen every 3, 6, 12 months or at every JSC (frequency not mentioned, most likely either 3 or 6 months). As explanations for missing evaluations are provided: "really hands-off alliance", "not yet implemented, JSC members not absolutely in favor" and "no formal evaluation, but we have the feedback from Merck JSC members".

As commonly measured KPIs "decision making" was provided six times. "Opportunities identified" and "joint/established objectives" was given as response three times, "follow up on action items/deliverables" twice. JSC/JPT member's individual feedback is collected in at least one of the alliances of one AM. The adherence to the timelines of dossier submission to regulatory authorities is measured in at least one of the alliances of another AM. One AM measures the value creation. The frequently mentioned KPIs are quite similar to the ones of the regular Merck Alliance Management survey as listed in Sect. 4.3. Three AMs would not introduce any additional KPIs, one "as few as possible". The others proposed adherence to budget and time, effective decision making, key milestones met or exceeded, alignment between internal and external goals, first 100 days onboarding and planned termination.

\subsection{Feedback on the 100-Day Plan}

Five AMs (56\%) have already some kind of a 100-day plan for alliance launch in use, four AMs (44\%) have not. As the three most important steps were mentioned mainly the very first steps:

- Arrange KOM (2 days with all project members, incl. definition of JPT)

- Appoint JSC and JPT members

- Alignment/good relationship with partner AM

- Align on joint objectives/operational plan for year one

- Ensure knowledge transfer from due diligence to operational team

- Align on governance and decision-making model 
- In addition, some general rules and principles are seen as the most important steps like

- Documentation of roles and responsibilities

- Development of a project plan and communication matrix

- Empowerment of project teams for decision-making

Five AMs do not consider any of the content in the proposed 100-day plan as less important than others. One AM sees "celebrations, motivational training and crosscultural analysis" as not so important. Another AM considers "IT infrastructure, alliance charter and sharepoints" (for exchange of data and documents, similar than IT infrastructure) as not so relevant. Both AMs are in charge of either "more transactional and vendor-type" alliances or commercial supply agreements which might not have relevant data exchange over a longer period of time compared to e.g. co-development alliances. One AM is of the opinion that "newsletter, survey with both partners at that point of time and lessons learned at that point of time" are not that relevant.

The survey results show that the proposed 100-day plan mainly lists relevant and important steps and was not including steps of low importance in the eyes of most of the survey participants. Six AMs do not have to add anything. One AM misses "full accountability", another AM wants to see the 100-day plan established at the beginning of an alliance: AM function shall therefore become involved earlier during due diligence and prior to deal closure. One AM prefers an early appointment of project leader/manager and its/their involvement into the activities prior to contract signature.

Overall the feedback by eight experienced practitioners shows that the proposed 100 -day plan already includes most of relevant steps and information.

\section{Conclusion and Outlook}

Some of the conclusions were already made directly in the analysis of the single results in the previous chapter. Therefore, only some general conclusions shall be presented here.

The elaborated 100-day plan has been well accepted by the AMs and their participation in the survey-both in terms of the $90 \%$ response rate as well as engagement and proposals-was excellent and above expectations. Due to its limited sample size and the focus on Merck with its specific framework and type of alliances, the result might be used in different environments and companies only with some adaptions. But for the situation at Merck not many things have been identified as missing or incorrect and the contents of the plan are considered as useful for the launch of an alliance.

After usage for a few upcoming kick-offs and launch phases of alliances, a review and further improvement in a workshop together with the relevant AMs should be considered as a next step. 
Additional effort could be spent on the creation of an excel-based decision tool that would provide the specific tasks and best decision-making and governance approach in dependence of the type of alliance/business model and the current stage of the lifecycle (please refer also to Sect. 3.2). That would allow newcomers to Merck and/other the AM department a quick and easy guidance. But also of value for experienced AMs if they enter into an alliance type or structure which they have not managed some time ago.

Another area of interest could be the further improvement of KPIs used for the regular AM survey by Merck but also the self-assessments in some of the alliances. For the knowledge transfer (from BD to AM/PL, from the DD team to the operational project team or also for newcomers to the alliance team in a later phase), the elaboration of a checklist on the required data, its structure and storage could be considered.

Acknowledgements Alliances are not only important for companies, but also for MBA students. Therefore, I want to thank those individuals who supported me on my journey to this thesis and made this program an interesting and memorable time.

First, I would like to express my deepest gratitude to my thesis mentor Harm-Jan Borgeld as Head of Alliance Management at Merck KGaA, who willingly accepted a company topic and made additional proposals. And to Guarino G. Junior as Alliance Manager who gave valuable suggestions and always constructive feedback. Thanks also to all Merck Alliance Managers who participated in the survey and provided feedback on their experiences and on the proposed 100-Day Plan.

Moreover, I am very grateful to Eva Koscher for mentoring and reviewing this thesis.

I would also want to express my sincere thanks to the Goethe Business School and the House of Pharma \& Healthcare, especially the Academic Directors Prof. Dr. Lars Schweizer and Prof. Dr. Theo Dingermann, for establishing the Master of Pharma Business Administration program. Thanks to the faculty members and guest lecturers for very interesting and interactive teaching and the willingness for flexibility. Thanks also to the program management staff for their kind support and cooperation.

I would like to cordially thank my fellow students of the inaugural Pharma MBA class at Goethe Business School for valuable insights, constructive discussions and a very friendly and productive atmosphere.

Finally, my deepest and most sincere gratitude goes out to Vanessa, Solveig and Rasmus. Thank you for your unconditional support and the acceptance of missed shared leisure time and activities with you over the last 2 years.

Last but not least, I would like to thank my employer, Merck KGaA, and especially my line manager Stephen Li, for giving me support and flexibility to pursue my professional development and the opportunity to transfer the acquired knowledge into practice.

\section{Appendix 1: Operational 100-Day Plan for Alliance Launch}

The appendix is available under http://www.goethe-business-school.de/fileadmin/ user_upload/Files/07_Master_of_Pharma_Business_Administration/MPBA2018_ PublicationHoerner-Appendix1-_00-DayPlan.pdf 


\section{References}

Albers, S. (2005). The design of alliance governance systems. Cologne, Univ., Diss., 2005. Cologne: Kölner Wissenschaftsverlag.

ASAP. (2016). Alliance management professional development guide. Edited by Association of Strategic Alliance Professionals. Available online at https://www.petersimoons.com/wp-con tent/uploads/2011/03/ASAP-Proffesional-Development-Guide.pdf [sic!].

Austin, M. (2008). Business development for the biotechnology and pharmaceutical industry. Aldershot: Gower.

Bamford, J. D., Gomes-Casseres, B., \& Robinson, M. S. (2003). Mastering alliance strategy. A comprehensive guide to design, management, and organization. San Francisco, CA: JosseyBass.

BeiGene. (2014). BeiGene receives clinical milestone payment for development of BGB-290. Available online at http://ir.beigene.com/phoenix.zhtml?c=254246\&p=irol-newsArticle_pf\& $\mathrm{ID}=2130065$

Cancer Research UK. (2018). Cancer Research UK and The Institute of Cancer Research, London, join forces with Merck in new drug discovery alliance. Available online at http://commercial. cancerresearchuk.org/cancer-research-uk-and-institute-cancer-research-london-join-forcesmerck-new-drug-discovery

Capo, F., Brunetta, F., \& Boccardelli, P. (2014). Innovative business models in the pharmaceutical industry: A case on exploiting value networks to stay competitive. International Journal of Engineering Business Management, 6(7), 23. https://doi.org/10.5772/59155.

Checkmate Pharmaceuticals. (2018). Checkmate pharmaceuticals announces strategic collaboration with Merck KGaA, Darmstadt, Germany and Pfizer to Evaluate Combination Therapy with CMP-001 and Avelumab. Available online at https://checkmatepharma.com/pdf/release8.pdf

de Man, A.-P. (2005). Alliance capability: A comparison of the alliance strength of European and American companies. European Management Journal, 23(3), 315-323. https://doi.org/10. 1016/j.emj.2005.04.009.

DePamphilis, D. M. (2018). Mergers, acquisitions, and other restructuring activities. An integrated approach to process, tools, cases, and solutions (9th ed.). London: Elsevier/Academic Press.

Duysters, G., de Man, A.-P., Luvison, D., \& Krijnen, A. (2012). The state of alliance management: Past, present future. Eindhoven: Association of Strategic Allianc Professionals.

Dyer, J. H., Kale, P., \& Singh, H. (2001). How to make strategic alliances work. Developing a dedicated alliance function is key to building the expertise needed for competitive advantage. MIT Sloan Management Review, 42(4), 37-43.

Gomes, E., Weber, Y., Brown, C., \& Tarba, S. Y. (2011). Mergers, acquisitions and strategic alliances. Understanding the process. Basingstoke: Palgrave Macmillan.

Gomes-Casseres, B. (1999). The alliance revolution. The new shape of business rivalry. 3. print. 1. Harvard Univ. Press paperback ed. Cambridge, MA: Harvard Univ. Press.

Heimeriks, K. H., \& Duysters, G. (2007). Alliance capability as a mediator between experience and alliance performance: An empirical investigation into the alliance capability development process. Journal of Management Studies, 44(1), 25-49. https://doi.org/10.1111/j.1467-6486. 2006.00639.x.

Heimeriks, K. H., Klijn, E., \& Reuer, J. J. (2009). Building capabilities for alliance Portfolios. Long Range Planning, 42(1), 96-114. https://doi.org/10.1016/j.lrp.2008.10.005.

Herrmann, F., \& Dressel, M. (2014). Strategic alliances in life sciences: Are you ready? Edited by Institute for Mergers, Acquisitions and Alliances (IMAA). Available online at https://imaainstitute.org/strategic-alliances-life-sciences-ready/

IMAP. (2012). Global Pharma \& Biotech M\&A Report - 2012. Available online at https://www. proman.fi/sites/default/files/Pharmaceuticals\%20and\%20biotech\%20industry\%20report\% 202012_0.pdf 
Kale, P., Dyer, J. H., \& Singh, H. (2002). Alliance capability, stock market response, and long-term alliance success: The role of the alliance function. Strategic Management Journal, 23(8), 747-767. https://doi.org/10.1002/smj.248.

Kramer, W. (2016). Challenges and options for drug discovery. In A. Schuhmacher, M. Hinder, \& O. Gassmann (Eds.), Value creation in the pharmaceutical industry: The critical path to innovation (Vol. 34, pp. 106-139). Weinheim: Wiley-VCH Verlag GmbH \& Co. KGaA.

Leap Therapeutics, Inc. (2018). Leap therapeutics announces collaboration with Merck KGaA, Darmstadt, Germany, and Pfizer to evaluate combination of TRX518, Avelumab, and chemotherapy in advanced solid tumors. Available online at http://www.investors.leaptx.com/phoenix. zhtml $\mathrm{c}=254460 \& \mathrm{p}=$ irol-newsArticle $\& \mathrm{ID}=2359396$

Merck KGaA. (2007). Merck KGaA acquires majority shareholding in Serono S.A. Available online at https://www.merckgroup.com/content/dam/web/corporate/non-images/investors/whyinvest/acquisitions/2007/en/2007-01-05-serono-EN.pdf

Merck KGaA. (2010). Merck KGaA and Millipore announce transaction. Available online at https://www.merckgroup.com/content/dam/web/corporate/non-images/investors/why-invest/ acquisitions/2010/us/2010-02-28-millipore-corporation-US.pdf

Merck KGaA. (2014). Merck announces global strategic alliance with Pfizer on Anti-PD-L1 to accelerate presence in immuno-oncology. Available online at https://www.merckgroup.com/ content/dam/web/corporate/non-images/press-releases/2014/nov/en/Strategic-Alliance-withPfizer-EN.pdf

Merck KGaA. (2015). Merck completes Sigma-Aldrich acquisition. Available online at https:// www.merckgroup.com/content/dam/web/corporate/non-images/press-releases/2015/nov/en/ Sigma-Aldrich-Acquisition-EN.pdf

Merck KGaA. (2017a). Merck divests biosimilars business to Fresenius. Available online at https:// www.merckgroup.com/content/dam/web/corporate/non-images/press-releases/2017/apr/en/ Biosimilars_Fresenius_EN.pdf

Merck KGaA. (2017b). Merck KGaA, Darmstadt, Germany, licenses four oncology research and development programs from Vertex and becomes a leader in DNA damage and repair. Available online at http://news.emdgroup.com/N/0/C02440372F9F1446C12580A5001DA3B7/\$File/Ver tex_EMD_US.pdf

Merck KGaA. (2018a). Annual Report 2017. Darmstadt. Available online at https://ar.merckgroup. com/2017/sites/default/files/downloads/en/merck_annual_report_2017/index.pdf-Report-EN. pdf

Merck KGaA. (2018b). Merck announces collaboration with Xian Janssen to launch INVOKANA ${ }^{\circledR}$ (canagliflozin) for the treatment of type 2 diabetes in China. Available online at https://markets. businessinsider.com/news/stocks/merck-announces-collaboration-with-xian-janssen-to-launchinvokana-r-canagliflozin-for-the-treatment-of-type-2-diabetes-in-china-1027361311

Merck KGaA. (2018c). Merck to sell Consumer Health to Procter \& Gamble. Available online at https://www.merckgroup.com/content/dam/web/corporate/non-images/press-releases/2018/apr/ en/Consumer-Health-Divestiture-EN.PDF

Munos, B. (2009). Lessons from 60 years of pharmaceutical innovation. Nature Reviews. Drug Discovery, 8(12), 959-968.

Nevin, M. (2016). Strategic alliance handbook - A practitioners guide to business-to-business. Milton Park: Taylor \& Francis Ltd.

Newron Pharmaceuticals S.p.A. (2011). Newron and Merck Serono to broaden collaboration on new therapies for Central Nervous System diseases. Available online at http://www.jsb-partners. com/downloads/08.pdf

Peng, M. W. (2014). Global strategic management (Third international ed.). Mason, OH: SouthWestern Cengage Learning.

PhRMA. (2018). Pharmaceutical Research and Manufacturers of America. Annual Membership Survey 2018. Available online at http://phrma-docs.phrma.org/download.cfm? objectid=13AC7EF0-90F1-11E8-8DCF0050569A4B6C 
Recordati S.p.A. (2010). RECORDATI: Accordo con Merck KGaA per Cardicor ${ }^{\circledR}$ in Italia. Available online at http://www.recordati.com/resources/Pubblicazione/ 90e724956c064cf0bf6ef55e8792f0f3_/2010-12-23.pdf

Scannell, J. W., Blanckley, A., Boldon, H., \& Warrington, B. (2012). Diagnosing the decline in pharmaceutical R\&D efficiency. Nature reviews. Drug Discovery, 11(3), 191-200.

Scholtyseck, J., Burhop, C., Kißener, M., \& Schaefer, H. (2018). Merck: From a pharmacy to a global corporation (1st ed.). Munich: C.H. Beck.

Stafford, E. R. (1994). Using co-operative strategies to make alliances work. Long Range Planning, 27(3), 64-74.

Steinhilber, S. (2008). Strategic alliances. Three ways to make them work. Boston: Harvard Business Review Press.

Suen, W. W. (2005). Non-cooperation - The dark side of strategic alliances. Basingstoke England. New York: Palgrave Macmillan.

The Pharma Letter. (2013). Merck KGaA links with Bristol-Myers for Glucophage promotion in China. Available online at https://www.thepharmaletter.com/article/merck-kgaa-links-with-bris tol-myers-for-glucophage-promotion-in-china

Thong, R. (2016). Biopharma R\&D partnerships. From David \& Goliath to networked R\&D (First ed.). London: Phizz Rx Publishing.

Tjemkes, B., Vos, P., \& Burgers, K. (2018). Strategic alliance management (Second ed.). London: Routledge.

Twombly, J., \& Shuman, J. (2010). The practice of alliance management in the biopharmaceutical industry. Washington: Edited by The Rythm of Business.

Vyriad Inc. (2018). Vyriad announces collaboration with Merck KGaA, Darmstadt, Germany, and Pfizer to evaluate oncolytic virus, Voyager-V1, in combination with anti-PD-L1 antibody, Avelumab, in phase 1 cClinical study for metastatic colorectal cancer. Available online at http://www.vyriad.com/2018/07/18/vyriad-announces-collaboration-merck-kgaa-darmstadt-ger many-pfizer-evaluate-oncolytic-virus-voyager-v1-combination-anti-pd-11-antibody-avelumabphase-1-clinical-study/

Yoshino, M. Y., \& Rangan, U. S. (1995). Strategic alliances. An entrepreneurial approach to globalization. Boston, Mass., Harvard Business School Press.

Open Access This chapter is licensed under the terms of the Creative Commons Attribution 4.0 International License (http://creativecommons.org/licenses/by/4.0/), which permits use, sharing, adaptation, distribution and reproduction in any medium or format, as long as you give appropriate credit to the original author(s) and the source, provide a link to the Creative Commons licence and indicate if changes were made.

The images or other third party material in this chapter are included in the chapter's Creative Commons licence, unless indicated otherwise in a credit line to the material. If material is not included in the chapter's Creative Commons licence and your intended use is not permitted by statutory regulation or exceeds the permitted use, you will need to obtain permission directly from the copyright holder.

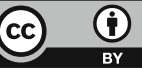

